\title{
Text-Relevant Video Segments and Reading Comprehension of Culturally Unfamiliar Texts with Adult Speakers of English as a Second Language (ESL)
}

\author{
Amirreza Karami ${ }^{1} \&$ Freddie A. Bowles ${ }^{1}$ \\ ${ }^{1}$ Department of Curriculum and Instruction, College of Education and Health Professions, University of Arkansas, \\ Fayetteville, AR, United States of America \\ Correspondence: Amirreza Karami, Department of Curriculum and Instruction, College of Education and Health \\ Professions, University of Arkansas, Fayetteville, AR, United States of America.
}

Received: August 19, 2021

Accepted: September 14, 2021

Online Published: September 15, 2021

doi: 10.5539/elt.v14n10p35

URL: https://doi.org/10.5539/elt.v14n10p35

\begin{abstract}
This pilot study is a mixed-methods sequential explanatory study that investigated the effects of watching text-relevant video segments supported by the Schematic Information-Processing (SIP) model of reading comprehension on reading comprehension of adult speakers of English as a Second Language (ESL) in terms of text familiarity and the retention of the content of a culturally unfamiliar text. Twenty homogeneous participants were randomly assigned to two groups: one control group and one experimental group. The results of the quantitative analysis showed that the experimental group outperformed the control group in both the immediate and delayed post-tests. Qualitative findings also highlight the effectiveness of implementing text-relevant video segments supported by the SIP model over traditional text-based reading instruction in terms of reading comprehension and retention of the content of the culturally unfamiliar passage. Limitations of the study and suggestions for future research are discussed in detail.
\end{abstract}

Keywords: The Schematic Information-Processing (SIP) model of reading comprehension, traditional text-based reading instruction, text familiarity, retention

\section{Introduction}

Reading comprehension is the ultimate goal of reading instruction (e.g., Nation, 2019; Smith et al., 2021; Snow, 2002; Spencer \& Wagner, 2018). In other words, reading comprehension is central to "academic progress, because it underpins content-area learning in all subjects" (Smith et al., 2021, p. 215). Successful reading comprehension is a complex and multifaceted process in the human mind. In fact, reading comprehension is an active and interactive process (Anderson, 1999; Grabe \& Stoller, 2002) between different cultural, linguistic, psycholinguistic, meta-cognitive, and cognitive aspects. Karami et al. (2021) divide the most critical factors affecting reading comprehension into internal and external factors. The individual's linguistic knowledge, background knowledge and experience, vocabulary knowledge, and internal motivation (e.g., Aferbach et al., 2017; Brevik, 2015; Brown, 2017; Fountas \& Pinnell, 2001; Hollenbeck, 2011; Karami, 2021; Snow, 2002; Woolley, 2011) are some internal factors while the cultural familiarity of the reader with the text (e.g., Carrell \& Eisterhold, 1983; Droop \& Verhoeven, 1998; Sabatin, 2013), the context, the text, and the teaching strategy applied by the teacher (Karami, 2021) are some of the external factors. Among all these factors, the teacher's teaching strategy is the only one of which the teacher has full control and can adapt based on their observations. Brevik (2019b, p. 2281) highlights this idea and argues that a deep understanding of a text "requires sustained emphasis on reading comprehension instruction and scaffolded strategy practices."

Although reading comprehension has been extensively researched in the literature, some scholars still believe that further investigation is needed (August \& Shanahan, 2006; Hwang \& Duke, 2020; Samson \& Lesaux, 2015). The review of the literature shows that "researchers apply the same set of models" to their research (Karami et al., 2021). Some examples of the most consistently applied models are the "Construction-Integration Framework (Kintsch, 1988, 1998; Kintsch \& van Dijk, 1978), the Dual-Coding Theory (Clark \& Paivio, 1991), the Cognitive Load Theory of Multimedia (Moreno \& Mayer, 1999), and the Generative Theory of Multimedia Learning (Mayer, 1997). 
This pilot study steps further and paves the way for future studies by taking a new reading comprehension model into consideration. The Schematic Information-Processing (SIP) model of reading comprehension (Karami, 2021) is a new model that provides theoretical support for the utilization of text-relevant video segments in reading instruction to teach culturally unfamiliar texts to English language learners (See Karami, 2021 for detailed discussion).

The purpose of this pilot study is to examine the relationship between text-relevant video segments and reading comprehension of culturally unfamiliar texts supported by the SIP model of reading comprehension (Karami, 2021) with adult speakers of English as a Second Language (ESL). The authors chose a culturally unfamiliar text and paired it with relevant video segments to investigate whether text-relevant video segments can improve the familiarity of the readers with the content of the text, their reading comprehension and retention. The following quantitative (Q1 and Q2) and qualitative (Q3) research questions were addressed:

1) Is there a significant difference in terms of reading comprehension between two types of reading instruction, watching text-relevant video segments supported by the SIP model of reading comprehension and the traditional text-based reading instruction, in adult speakers of English as a Second Language (ESL)?

2) Is there a significant difference in terms of the retention of the content between two types of reading instruction, watching text-relevant video segments supported by the SIP model of reading comprehension and the traditional text-based reading instruction, in adult speakers of English as a Second Language (ESL)?

3) How do text-relevant video segments help adult speakers of English as a Second Language (ESL) comprehend a culturally unfamiliar text?

\section{Review of the Literature}

The history of using audio-visual materials, as a supplementary tool, in classrooms goes back to World War II when filmstrips were used to train soldiers (Hovland et al., 1949). Since then, the innovation of technology and the development of new teaching methods have helped educators recognize "the power of audio-visual materials to capture the attention of learners, increase their motivation and enhance their learning experience" (Cruse, 2007, p. 1). Video players and televisions then become the simplest and the most accessible technology in language classrooms in different parts of the world which makes videos and video segments one of the most important teaching tools in classrooms.

"The utilization of videos in reading instruction is a familiar strategy across the curriculum" (Karami, 2021, p. 2) and has been investigated extensively in the past. The findings of previous studies also highlight the idea that videos can promote learning. Concerning second/foreign language pedagogy, for example, the findings show significant impacts of using videos in classrooms (e.g., Arthur, 1999; Canning-Wilson, 2000; Hemei, 1997; Lin, 2016; Wright, 1976). For example, Lin (2016) conducted a study to find the effects of video-based instruction on text comprehension of the second language learners and reported significant beneficial effects of video-based materials on overall comprehension of the text. Some other researchers (Caspi et al., 2005) focused on other areas such as students' preferences and argued that video-based reading instruction can be either promising or unfavourable for students depending on their learning habits and preferences.

An overall review of the articles related to the utilization of audio-visual materials in language learning classrooms, in general, and videos and reading comprehension, in particular, shows the efficacy of this language teaching strategy (Karami et al., 2021). In fact, most of the studies have reported the positive effects of using full-length or short videos on various aspects of language learning (Akbulut, 2007; Caspi et al., 2005; Lin, 2016). For example, Webb and Rodgers (2009a) highlighted the benefits of watching videos in the target language and stated that these resources can improve language learning due to the repetition of the target language and viewers' exposure to it. The review also shows that video-based reading instruction was based on the same set of theories such as the Cognitive Theory of Multimedia (Moreno \& Mayer, 1999), the Dual-Coding Theory (Clark \& Paivio, 1991), the Construction-Integration Model (Kintsch, 1988, 1998; Kintsch \& van Dijk, 1978), and the Cognitive Components-Resource Model (Atkinson \& Shiffrin, 1971).

This pilot study was based on the guidelines of the Schematic-Information Processing (SIP) model of reading comprehension developed by Karami (2021). According to Karami (2021), the SIP model is a theoretical framework that

...provides theoretical support and evidence for the positive effects of using text-relevant video segments

to teach culturally unfamiliar texts in second/foreign language classrooms. According to the SIP model, 
appropriate and well-chosen text-relevant video segments should be played in three stages of reading instruction: pre-reading, while-reading, and post-reading as the text is being read in the classroom. It is important to include text-relevant video segments in all three stages because 'the methodology of inserting the supplementary videos is very important for improvement of teaching' (Ljubojevic et al., 2014, p. 287). It should be mentioned that text-relevant video segments are playing a supportive role in this model which means that they should be considered as supplementary tools in teachers' toolbox. (p. 3)

\section{Methodology}

\subsection{Purpose of the Study}

Although previous studies have investigated the effects of watching videos on reading comprehension, vocabulary acquisition, and other areas of language, no study has investigated the effects of watching text-relevant video segments on reading comprehension of culturally unfamiliar texts in terms of text familiarity and retention of the text. This pilot study fills this gap by interpreting the results of both qualitative and quantitative data and paves the way for future studies. The combination of both will provide "a more complete and synergistic utilization of data" (Wisdom \& Creswell, 2013, p. 1).

\subsection{Participants of the Study}

Twenty international graduate students were selected and assigned to two different groups: a control group and an experimental group. The participants were enrolled at a mid-southern land grant institution of almost 28,000 students in the United States of America. Convenience sampling was used since participation was voluntary. Participants of this study were all from Iran. Farsi was their first language. They all had learned English in an English as a Foreign Language (EFL) setting (Iran). Although participants were raised in different cities of Iran with specific microcultures, they all shared the greater Iranian culture.

\subsection{Homogeneity of the Participants}

Each group had 10 participants composed of six males and four females. The participants were randomly assigned to either the experimental group or the control group. The average age of the participants was thirty-three years old $(M=33)$ and all had learned English as their second language in an EFL setting. Since they were graduate students majoring in different disciplines, they had met the minimum admission requirements of the university such as the Graduate Record Examination (GRE) and an English language proficiency test. The participants of this study had a minimum score of 6.5 on the International English Language Testing System (IELTS), or a minimum score of 79 on the Internet-based Test of English as a Foreign Language (TOEFL).

Participants were selected based on their unfamiliarity with a culturally specific topic, American football. The content of a reading passage that discussed the rules of the game was both culturally and linguistically unfamiliar to the participants because American football is neither played nor televised in Iran. Therefore, participants were most likely homogeneous in terms of their cultural knowledge and experience, as well as their prior knowledge of American football.

A pre-test was administered to ascertain the unfamiliarity of the participants with the topic and the content of the reading passage. The minimum score was 1 out of 20 and the maximum score could be 20 out of 20 . The results of the pre-test showed that the control group $(M=1.30, S D=.483)$ and the experimental group $(M=1.40, S D=.516)$ had almost the same mean scores and standard deviations of the same low magnitude which means the participants of the study were not familiar with American football and its rules and regulations.

\subsection{Research Instruments}

An article about American Football by Osorio (2011) was chosen and adapted for this study. The short article, three and a half pages, focused on the basic rules and regulations of American football. The article starts with a brief description of American football and moves to some factors and variables that can affect the results of the game.

Two authentic video segments about American football were selected and used as a part of the instruction of the experimental group. The video segments were produced for English native speakers and were chosen from the YouTube channel. One of the video segments was taken from the NFL (National Football League) website (https://www.youtube.com/watch?v=3t6hM5tRlfA), which was one minute and 19 seconds long, and the second $\begin{array}{lllllll}\text { video segment was minutes and } 20 \text { seconds long } & \end{array}$ (https://www.youtube.com/watch?v=Ddwp1HyEFRE\&vl=tr).

The total number of 11 questions designed to measure the participants' comprehension and retention of the text included ten closed-response questions consisting of fill in the blank, multiple-choice, short answer, and true or 
false with one open-response question. The same set of questions was administered in three stages: pre-test, immediate post-test, and delayed post-test. Figure 1 shows an example of the reading comprehension questions.

\section{Reading Comprehension Questions}

\section{Participant Code:}

1) The main point of this article is about
a) Popularity of American football in the world
b) Rules and regulations of American football
c) Introducing the American football field
d) Cooperation and collaboration of the players in the field

2) According to the article, how many ways are there for a team to gain points in American football?
a) One
b) Two
c) Three
d) Four

Figure 1. An Example of the Reading Comprehension Questions

The reading comprehension questions were carefully designed by the researchers and reviewed by two literacy experts not only to cover different parts of the text but also to include different formats as well. The first ten questions measured recall of the details of the passage; i.e., the basic rules and regulations of American football and how teams gain scores.

The last question was a descriptive question focused on the overall understanding of the text by asking the participants to provide a summary of what they learned from the one-session instruction about American football without concern for grammar, spelling, and punctuation. The purpose of this descriptive question was to compare the experimental group with the control group in terms of their recall and retention.

Qualitative data were collected using a semi-structured interview with two randomly selected participants from each group to answer the third research question. The number of interview questions for the control group was seven and for the experimental group 13. The first seven questions concerned participants' feelings, motivation, perception, background knowledge, and prior experience. Figure 2 shows an example of interview questions designed for both groups.

1) How did you feel about the text?

2) Was the text culturally familiar to you? Why?

3) Could you make a connection between the text and your background knowledge or prior experience? Can you please explain more?

Figure 2. Examples of Interview Questions Designed for Both Groups

The experimental group had six additional questions about the effects of watching video segments on activating prior knowledge and cultural experiences. Figure 3 shows an example of interview questions designed specifically for the experimental group.

8) Do you think that text-relevant video segment helped you in the comprehension of the text? Why or why not?

9) How do you feel about the video(s)?

10) Did you connect the video to your background knowledge or prior experience? How?

Figure 3. Examples of Interview Questions for the Experimental Group 


\subsubsection{Reliability and Validity of the Instruments}

The results of the immediate and delayed post-tests were used to find the test-retest reliability of the tests. Test-retest reliability is used to measure the consistency of the tests over time. Test-retest correlation was reliable and significant $(r=.785, p<.05)$. Figure 4 shows this correlation.

\section{Test Retest Correlation}

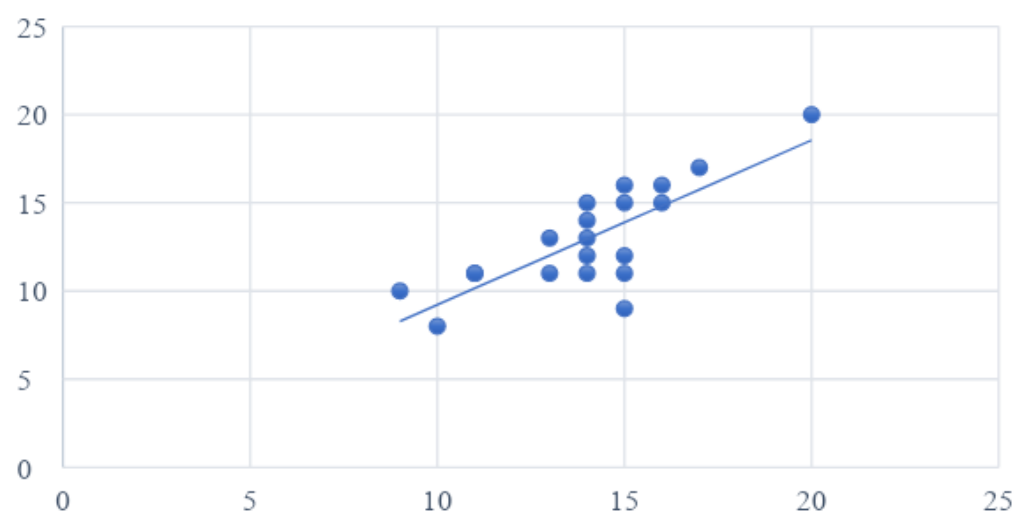

Figure 4. Test-Retest Correlation

The intraclass correlation was also used to avoid overestimate relationships due to the small sample size in this study. The result of the intraclass correlation is also significant $(\mathrm{p}<.05)$ and indicates good reliability between the two tests. Table 1 shows the results of the intraclass correlation performed by SPSS 24 .

Table 1. Intraclass Correlation Coefficient

\begin{tabular}{lllllll}
\hline & Intraclass Correlation & $\mathbf{9 5 \%}$ CI & & & \multicolumn{2}{c}{ F Test with True Value 0 } \\
\cline { 1 - 1 } Lower Bound & Upper Bound & Value & $\boldsymbol{D f} \mathbf{1}$ & $\boldsymbol{D} \boldsymbol{f} \mathbf{2}$ & $\boldsymbol{P}$ \\
Single measures & .729 & 7.836 & 19 & 19 & .001 \\
Average measures & .843 & 7.836 & 19 & 19 & .001 \\
\hline
\end{tabular}

Both sets of questions, comprehension and interview questions, were reviewed by two language experts to make sure that they were valid in terms of face validity and content validity. This was done to make sure that questions measured what they were expected to measure.

\subsection{Variables}

Two independent variables and one dependent variable were identified in this study. The independent variables of this study are as follows:

- Teaching strategy as the between-subjects factor with two levels: traditional vs. video-based.

- Time as the within-subjects factor with two levels: immediate post-test (IPT) and delayed post-test (DPT).

Reading comprehension is the only dependent variable of this study. Since the study includes two independent variables with two levels of each and one dependent variable, a $2 * 2$ Mixed ANOVA was performed to analyse the data.

\section{Assumptions of $2 * 2$ Mixed ANOVA}

Uttley (2019) states that "Parametric tests rely on certain assumptions about the way in which data were collected and the way in which they are distributed" (p. 145). He emphasized four assumptions that must be tested in parametric tests;

a) The dependent variable must be measured on an interval scale.

b) Data should be collected independently from each other.

c) Data should be normally distributed.

d) There should be homogeneity of variance. 
To begin with the first assumption, reading comprehension scores were recorded on an interval scale through the administration of tests in such a way that the difference and distance between scores were meaningful. The second assumption was also met because the participants of the study did not influence each other in terms of data collection. Each group received different treatments, and the responses from one participant to another were independent. The assumption of normality was checked through the evaluation of graphical representation, descriptive statistics, and "statistical tests of deviation from normality" (Uttley, 2019, p. 150).

Table 2 shows the results of tests of normality. The values of the Shapiro-Wilk test show that the data were normally distributed in all teaching modes except for the video-based instruction in the immediate post-test ( $p$ $<.05)$.

Table 2. Tests of Normality

\begin{tabular}{llll}
\hline Variable & \multicolumn{1}{l}{$\boldsymbol{P}$} \\
\hline \multirow{2}{*}{ Immediate Post-Test } & Kraditional & .199 & .313 \\
& Reading with Video Segments & .067 & .018 \\
Delayed Post-Test & Traditional & .164 & .441 \\
& Reading with Video Segments & .200 & .692
\end{tabular}

The output of the normal Q-Q plot (Figure 5) for the video-based instruction in immediate post-test shows that the magnitude of the violation is small. While an ANOVA test can be used for small violations (Uttley, 2019), some researchers (Field et al., 2012) also state that an ANOVA is fairly robust to violations of homogeneity of variance in groups that have equal sample sizes such as the equal sample sizes of this study. Schmider et al. (2010) highlighted this and argued that results will still be close to the results of the normal distribution even if there is a minor violation of the assumption of normality. Therefore, the minor violation of the data in the results of the immediate post-test in video-based instruction can be ignored.

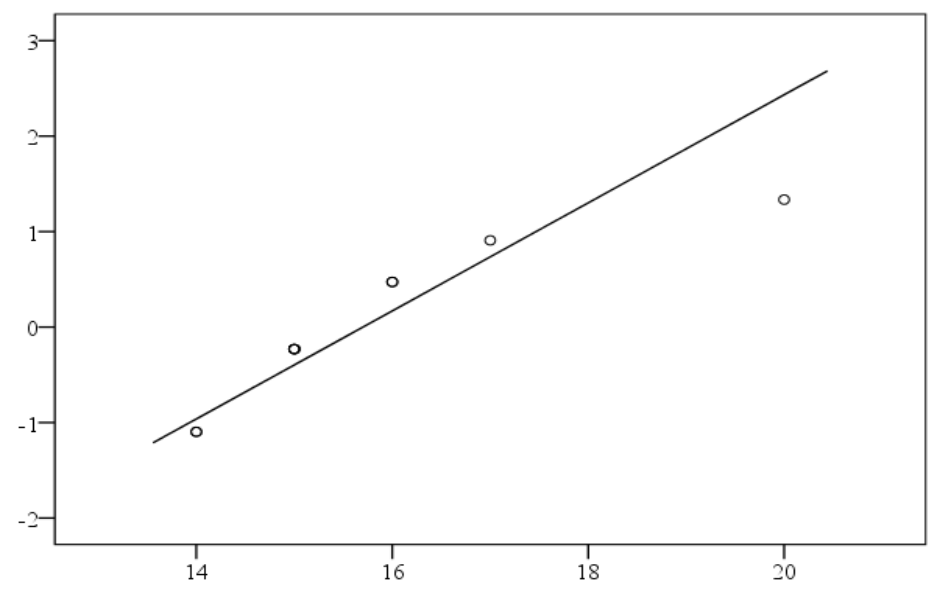

Figure 5. Normal Q-Q Plot for the Results of the Experimental Group's Immediate Post-Test

To check the homogeneity of variance, "Levene's test can be used to test whether this assumption of homogeneity of variance is true" (Uttley, 2019, p. 151). Table 3 shows the results of this test. Since there is no significant result in this test, the data meet this assumption as well; therefore, according to the testing of assumptions, a $2 * 2$ Mixed ANOVA is an appropriate parametric test for this study.

Table 3. Levene's Test of Equality of Error Variances

\begin{tabular}{lllll}
\hline & $\boldsymbol{F}$ & $\boldsymbol{d f} \mathbf{1}$ & $\boldsymbol{d f} \mathbf{2}$ & $\boldsymbol{P}$ \\
\cline { 2 - 5 } Immediate Post-Test & 1.061 & 1 & 18 & .317 \\
Delayed Post-Test & .813 & 1 & 18 & .379 \\
\hline
\end{tabular}




\section{Reliability and Validity of the Instruments}

The results of the immediate and delayed post-tests were used to find the test-retest reliability of the tests. Test-retest reliability is used to measure the consistency of the tests over time. The results showed evidence of test-retest reliability. Test-retest correlation is significant with $p<.05$ and reliable with Pearson's $r=.785$.

Both sets of questions, comprehension and interview questions, were reviewed by two language experts to make sure that they were valid in terms of face validity, content validity, and construct-related validity to make sure that questions measured what they are expected to measure.

\section{Intervention}

The experimental group received one sixty-minute treatment session. The participants in this group read the text about American football and watched two video segments during the instruction. The control group read the same text during the sixty-minute session without any video support but with the same instruction.

To familiarize the participants of the experimental group with the rules and regulations of American football, a video segment (one minute and 19 seconds) was played at the beginning of the sixty-minute session. This video segment served as an introduction to American football including such facts as the number of participants of each team, the length of the game, the aim of the game, and the name of some techniques performed in this game.

Participants in the experimental group were then directed to begin the reading passage. At the appropriate section in the text, some parts of the second video segment were played based on the content of the reading passage and the context of the video. For example, if the paragraph was about the techniques of the game such as interception, that part of the second video was chosen and played about interception. The second video was viewed in its entirety during the reading. When the participants concluded reading the passage, the first and second video segments were played again without stopping to confirm and stabilize the input that they had received during the session.

The control group had a sixty-minute session without exposure to the video segments. This group simply read the passage and received the same instruction as the experimental group without watching the video segments.

Both groups received immediate post-test questions at the end of the treatment session and were not allowed to use the text to answer the reading comprehension questions. One week later, both groups received and answered the same set of questions as the delayed post-test. The participants of the study knew in advance that they would receive three tests as their pre-test, immediate post-test, and delayed post-test due to the consent forms that they had signed before participating in this study. The same tests were administered in three stages including a pre-test, an immediate post-test, and a delayed post-test to measure participants' retention, their over-time progress, and to achieve meaningful results regarding comprehension. Having both groups receive the same test administration and questions, assured there would be no test bias. In addition, participants' answers to the open-ended question showed whether their answers to reading comprehension questions were most likely due to learning or by chance.

\section{Results of the Study}

\subsection{Quantitative Results}

Statistical Package for Social Science (SPSS) 24 was run to answer the first and second research questions. The results of the descriptive statistics show that the mean score of the control group $(M=12.40, S D=2.01)$ is lower than the mean score of the experimental group $(M=15.70, S D=1.76)$ in the immediate post-test (IPT). According to the results, the overall performance of the experimental group was better than the overall performance of the control group in terms of the comprehension of the culturally unfamiliar text.

The results of the descriptive statistics also show that the participants of the experimental group retained the content of the reading passage longer than the participants of the control group. The experimental group in the delayed post-test (DPT) has greater mean and data variability $(M=15.10, S D=2.514)$ than the control group in the DPT $(M=10.90, S D=1.595)$. In fact, the mean score of the experimental group showed a smaller decrease from immediate $(M=15.70)$ to delayed post-test $(M=15.10)$. In contrast, the mean score of the control group decreased more from immediate $(M=12.40)$ to delayed post-test $(M=10.90)$. The difference is .60 for the experimental group while the difference is 1.50 for the control group. This indicates that watching text-relevant video segments supports the retention of the content of a culturally unfamiliar passage in this study.

To answer the first research question, the Tests of Between-Subjects Effects were performed. The results of the Tests of Between-Subjects Effects show a significant effect of the teaching strategy on the reading comprehension of the text. The main effect for reading mode yielded $F(1,18)=22.233, p<.001$ indicating a significant difference between using video segments $(M=15.70, S D=1.76)$ and no video as the medium of instruction $(M=12.40, S D=$ 2.01). Table 4 shows a summary of the SPSS output. 
Table 4. Tests of Between-Subjects Effects

\begin{tabular}{|c|c|c|c|c|c|c|c|c|}
\hline & \multicolumn{2}{|c|}{ Experimental Group } & \multicolumn{2}{|c|}{ Control Group } & \multirow[b]{2}{*}{$d f$} & \multirow[b]{2}{*}{$F$} & \multirow[b]{2}{*}{$P$} & \multirow[b]{2}{*}{$\eta_{p}^{2}$} \\
\hline & $M$ & $S D$ & $M$ & $S D$ & & & & \\
\hline Reading Mode & 15.70 & 1.76 & 12.40 & 2.01 & 1 & 22.233 & .001 & .553 \\
\hline
\end{tabular}

To answer the second research question, a test of Within-Subjects Effects was performed. The results showed a significant difference between participants' retention in the video vs. traditional mode. The results show a statistically significant relationship between post-test scores $F(1,18)=6.517, p<.05$, which indicates that the video-based instruction had significant effects on the results of the post-tests. In other words, a significant relationship between teaching strategy (traditional vs. video-based) and longer retention of the content of the culturally unfamiliar text of adult speakers of English as a Second Language (ESL) is revealed in this study. The interaction effect between post-tests and reading modes was not significant $F(1,18)=1.197, p>.05$, but there is an ordinal interaction between them. Table 5 provides a summary of the SPSS output.

Table 5. Tests of Within-Subjects Effects

\begin{tabular}{lllll}
\hline & $\boldsymbol{d} \boldsymbol{f}$ & $\boldsymbol{F}$ & $\boldsymbol{P}$ & $\boldsymbol{\eta}_{\boldsymbol{p}}{ }^{2}$ \\
\hline Post Tests * Reading Mode & 1 & 1.197 & .288 & .062
\end{tabular}

The ordinal interaction indicates that both reading the passage and watching video segments were influential strategies for reading comprehension. It is also worth noting that including text-relevant video segments in two stages of reading instruction promoted retention. The group with videos outperformed the group with no video segments in post-test scores indicating the efficacy of including video segments in teaching the culturally unfamiliar text. The results also show a minimal reduction in the scores of the experimental group from immediate to delayed post-test while the scores of the control group were more reduced than the scores of the experimental group. This indicates that including text-relevant video segments in reading instruction helps the retention of the content and the level of retention of the culturally unfamiliar text.

To examine the retention level of the participants, Question 11 (open-response question) was graded holistically on both the immediate and delayed post-tests. The scoring rubric was adapted from a recommended holistic rubric by Kelley and Clausen-Grace (2007). The scores of the rubric ranged from one (the lowest score) to five (the highest score). A "five" indicates that the participant provided a good summary of the text that is comprehensible and accompanied by the correct responses regarding the rules and regulations of American football while a "one" indicates a poor summary that is incomprehensible with little to no understanding of the rules and regulations. Figure 6 shows a comparison of the holistic scores of the two groups of the study in both immediate and delayed post-tests.

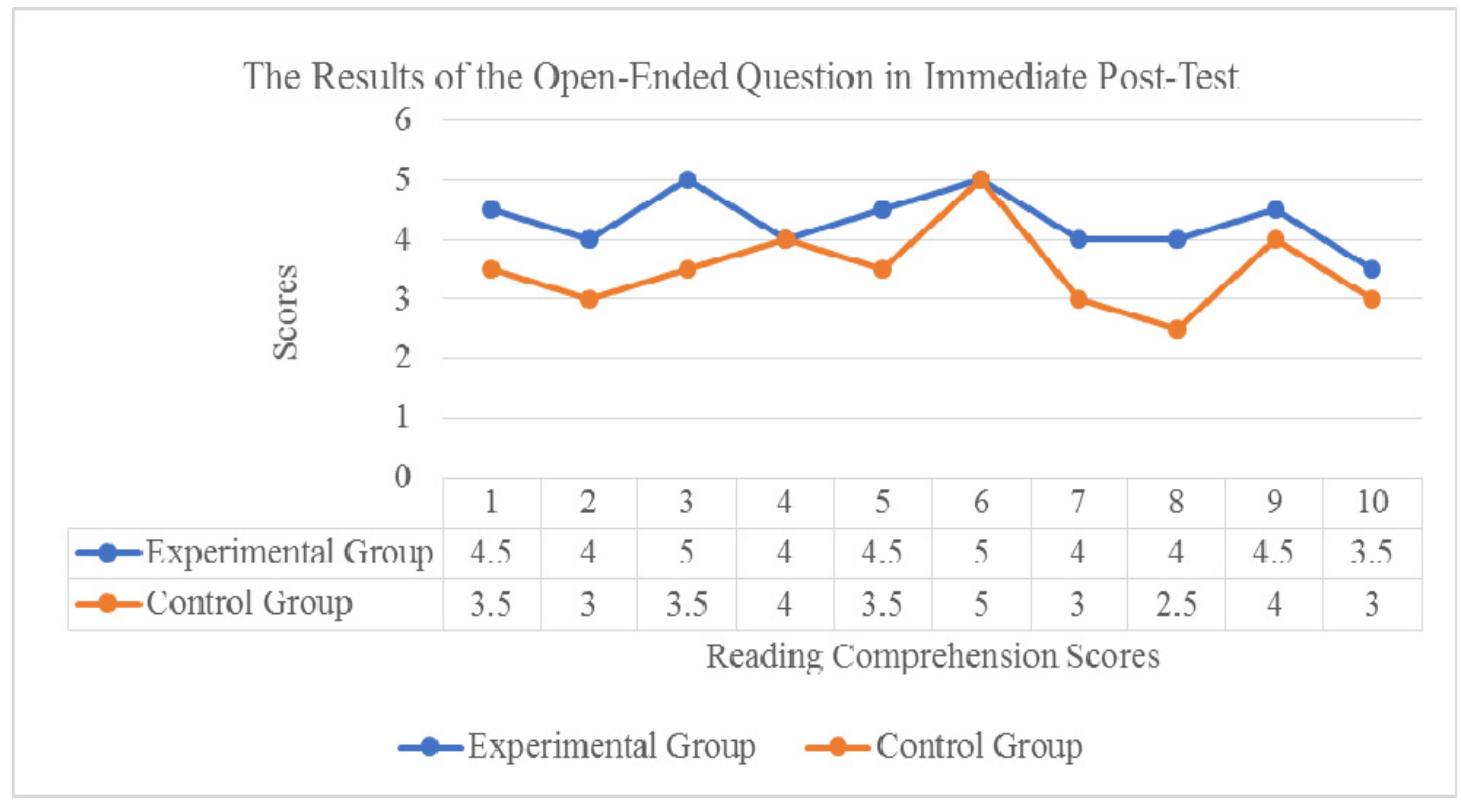

Figure 6. The Results of the Open-Ended Question in the Immediate Post-Test 
The results of the open-ended question show that the experimental group had better overall comprehension of the passage, receiving higher scores in comparison to the control group. The mean score of the experimental group is $4.3(M=4.3)$ out of 5 which is 0.8 greater than the mean score of the control group $(M=3.5)$ indicating that text-relevant video segments were beneficial in the comprehension of the culturally unfamiliar reading passage for this study.

To compare the retention level of these two groups, the results of the delayed post-test were also demonstrated in Figure 7.

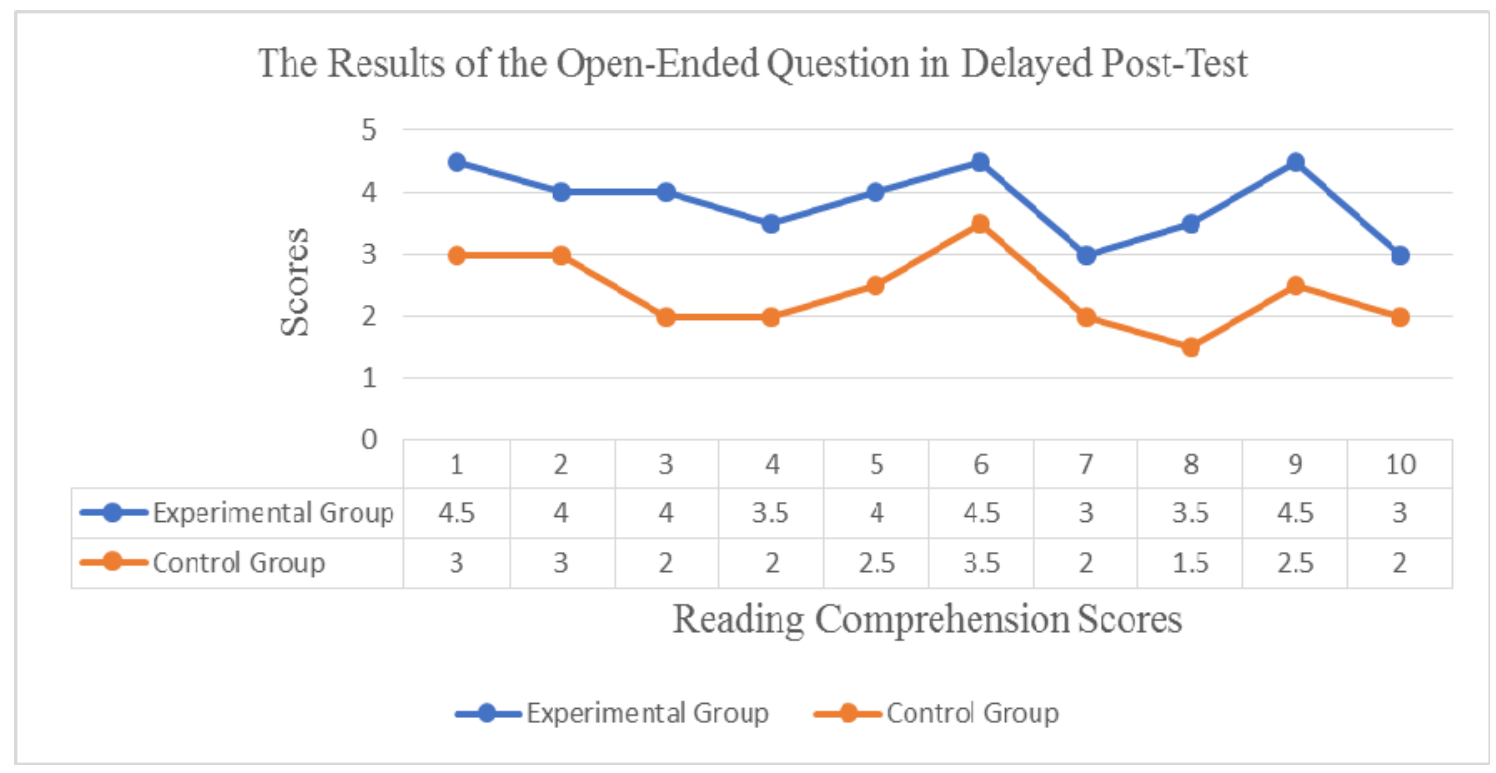

Figure 7. The results of the open-ended question in the delayed post-test

The results of the open-ended question in the delayed post-test (DPT) show that the scores of both groups have decreased from immediate to delayed post-tests. The comparison of the results between the two groups in the DPT shows that the experimental group still has the higher scores between the two groups after one week. The mean score of the experimental group, in the delayed post-test $(M=3.85)$, is 1.45 points greater than the mean score of the control group $(M=2.4)$. This indicates that the video segments had positive effects on the overall retention level of text-based information among members of the experimental group.

The results of the inferential statistics show that integrating text-relevant video segments with text can facilitate the comprehension process and improve the comprehension of a culturally unfamiliar text. The improvement in the comprehension of the text points to better retention of the content of the text as well.

\subsection{Qualitative Results}

Interview responses were transcribed, followed by initial coding to highlight words or phrases that were repeated or appeared to stand out. Saldaña $(2009$, p. 81$)$ states that initial coding "is not necessarily a specific formulaic method." These words and phrases were then reviewed a second time to look for themes. Creswell (2013) states that re-coding of data after the initial cycle of coding also helps the researcher improve the reliability of the findings. Following the guidelines of the thematic analysis outlined by Braun and Clarke (2006), three themes were identified: culturally unfamiliar texts, multiple strategies, and text-relevant videos with deeper levels of processing information.

\subsubsection{Culturally Unfamiliar Texts}

Interviewees of both the control and the experimental group believe that the text was useful, informative, and easy to read. Interviewees also acknowledged that it was their first time reading and learning about American football.

One of the control group interviewees answered, "Honestly, I had no idea about American football," showing cultural unfamiliarity. The other control group interviewee stated that "there was no overlap between American football and my own culture." One of the interviewees stated that he had seen some players "passing the field... and I was watching the players from outside," showing that he/she was curious about American football. 
Interviewees of the experimental group mentioned the importance of videos and their roles in the comprehension of the text. "Basic things are explained very well." One of the interviewees highlighted some features that the videos could clarify such as the number of players.

Since soccer is played in the interviewees' home country, it is expected to see a connection between these two sports in the individual's mind indicating the integration of ideas with prior knowledge and the formation of "a strategically associated memory structure about the content" (Wijekumar et al., 2018, p. 1974). Two interviewees of the control group reported that they could not make any connection between the text and their prior experience indicating a lack of schema regarding American football, which could hinder the successful comprehension of the text. One of the interviewees of the control group mentioned a lack of connection between American football and his/her prior knowledge and stated that "There is no connection between American football and other sports that I know of." This was confirmed by a second interviewee from the control group saying that "I could not make connections." The interviewee believed that some basic terms were the same as soccer, which is well-known and played in his/her country but was not a very deep connection. The reason for the lack of connection between American football and soccer for these individuals could be that they might know less about soccer, or it could be about reading.

This is also true for the participants of the experimental group. They had no idea and could not make any connections to their background knowledge except for the number of players and some basic terms such as defensive or offensive, which are the same terms used for soccer players in their country. One of the interviewees reported that he could make a connection between soccer and American football while watching video segments because of these similar terms.

One of the interviewees of the experimental group mentioned the role of text-relevant video segments in remembering the answers to the reading comprehension questions and said, "When we watched the video, after that, following the text was kind of easier for me."

\subsubsection{Multiple Strategies}

Interviewees reported positive effects of reading the text on their understanding of American football. "Despite the efforts of some of my American friends explaining American football to me, this passage really helped me, and I learned a lot of things about it." One of the interviewees from the control group stated that even though he had been to the stadium before and had watched American football in the stadium, he had no clue how American football was played and what the rules were before reading this passage. It is clear from this sentence that only watching video segments is not enough and cannot lead to successful comprehension of the culturally unfamiliar text. The interview responses indicate that the integration of video segments and reading was more beneficial.

One of the interviewees from the experimental group talked about his/her feelings towards American football after reading this text and said, "I have a good feeling about American football right now, and I think I understand all of it." Videos along with reading instruction, as an integrated strategy, can facilitate the comprehension process of the culturally unfamiliar text. Interviewees of the experimental group emphasized that watching the video segments for the second time (while-reading stage) and discussing the rules simultaneously clarified the text.

\subsubsection{Text-Relevant Videos with Deeper Levels of Processing Information}

Interviewees of the experimental group mentioned the role of text-relevant video segments in understanding the culturally unfamiliar text. They stated that the "video was great. In the video, it was the basic concept about everything." The interviewees of the experimental group mentioned that text-relevant video segments also enhanced their interest and motivation to learn more about American football. One of them stated that "without video, I was not interested to follow, actually, this subject."

Concerning the level of interest and the motivation that text-relevant video segments could provide, interviewees reported positive effects. For example, one interviewee from the experimental group mentioned the role of video in enhancing motivation and stated that "video was a great kind of motivation to follow the text." The interviewees of the experimental group also talked about the long-term effects of watching text-relevant video segments and argued that they would like to follow American football, find games on the Internet, or go to the stadium to watch the game. This shows that reading about American football and watching text-relevant video segments promoted their motivation and interest in such a way that they want to continue learning more about it.

With respect to the role of text-relevant video segments and their effectiveness on vocabulary learning, interviewees answered, "Yes, exactly." They believed that text-relevant video segments explained technical words very clearly and clarified their meanings. One of the interviewees of the experimental group could remember some words. The interviewee believes that he/she remembers words because of watching the text-relevant video 
segments. One of the experimental group interviewees mentioned the role of videos and said, "I mostly remember the video."

Interviewees of the experimental group also mentioned the positive role of videos in understanding some technical words that they had not heard before. Control group interviewees mentioned the problems that they had in terms of vocabulary and stated that they needed some extra help such as Google to understand the meaning of those words. Learning words incidentally through watching videos related to the text can provide readers with an opportunity to see the authentic use of the words produced by native speakers in the target culture (Karami, 2019).

Interviewees were also asked to provide researchers with any suggestions that they thought were important. One of the interviewees of the control group mentioned figures and pictures. The interviewee said, "I was reading through the text and then I was like hey, what does it mean. Then I was trying to imagine what it means or how it looks like in reality. I wish you had some pictures in that to show it." Interviewees also believe that a combination of text and related videos can lead to even more successful comprehension although one of them said that "I think video, alone, can help a lot."

The findings of the thematic analysis also highlight the effectiveness of the utilization of text-relevant video segments in the three stages of reading instruction. According to the interview responses, watching text-relevant video segments helped readers retrieve their prior knowledge and experience, facilitated the comprehension process, and promoted reading comprehension of the culturally unfamiliar text. Watching text-relevant video segments also enhanced readers' interest and motivation and provided readers with a clear picture and outline of the game.

\section{Limitations and Suggestions}

This pilot study investigated the effects of watching text-relevant video segments supported by the Schematic Information-Processing (SIP) model of reading comprehension on reading comprehension of a culturally unfamiliar text with adult speakers of English as a Second/Foreign Language (ESL/EFL). The sample size of this study was small with 20 adult international graduate students of the same nationality. Future studies need to be conducted with larger sample sizes and various linguistic and cultural backgrounds to help the generalizability of the results.

The participants of this study were all adults with the same English language proficiency level. Future studies could be conducted with younger students to examine the effect of watching text-relevant video segments on their reading comprehension. The treatment session was limited to reading one text in one 60 -minute session. Future research could extend sessions to multiple texts and sessions with longer periods of time to see the results and delayed effects of the instruction on second/foreign language learners' language proficiency in terms of cultural familiarity, reading comprehension, listening, speaking, vocabulary knowledge, grammar, and students' feelings and perceptions before and after watching the video.

This study did not differentiate between males and females in terms of their cultural knowledge. Therefore, future studies could consider this by comparing a group of males with a group of females to find out whether gender stereotypes affected the participants' understanding about American football or their prior knowledge about soccer and other sports that could have been relevant.

This study compared video-based reading instruction with traditional text-based reading instruction. Future studies could compare other classroom instructions with video-based instruction to see which instruction leads to more successful comprehension of culturally unfamiliar texts.

\section{Discussion and Conclusion}

This pilot study addressed three research questions. Concerning the first research question, the findings showed that there is a significant difference between watching text-relevant video segments supported by the Schematic Information-Processing (SIP) model of reading comprehension and the comprehension of a culturally unfamiliar text of adult speakers of English as a Second Language (ESL). The results imply that playing text-relevant video segments in three stages of reading instruction could cover various aspects that are necessary for successful comprehension of a culturally unfamiliar text like retrieving background knowledge, the construction of schemas, and providing scaffolding.

For the second research question, the results showed that there is a significant difference between the comprehension and retention of the content between the two groups. Although the interaction effect between post-tests and reading modes was not significant, an ordinal interaction between them illustrates a relationship. This implies the idea that viewing text-relevant video segments in three stages of reading instruction could help 
readers repeat and review the content once more, provide an opportunity for them to see the use of words and sentences in real-life situations, and help them remember the content of the text longer.

The third research question focused on the participants' views and addressed how text-relevant video segments could help adult speakers of English as a Second Language (ESL) comprehend a culturally unfamiliar text better. Interview responses highlighted the applicability of text-relevant video segments in reading instruction in such a way that playing text-relevant video segments in three stages is a multiple-layered strategy that can improve deeper levels of information processing.

Since language learning is a process of active interactions between various sources such as linguistic, cultural, conceptual, emotional, and prior experience, researchers and teachers need to have a closer look into reading comprehension models in general and models of video-based instruction to teach reading specifically. For example, Bohn-Gettler (2019) proposed the Process, Emotion, and Task (PET) framework to study the complexity and the influence of readers' emotions on comprehension. Bohn-Gettler (2019, p. 387) stated that "studies must consider the specific comprehension process under investigation, identify the processes likely to be influenced by emotion, and provide hypotheses for how these processes may be influenced by emotion." Playing text-relevant video segments in three stages of reading instruction not only motivates readers but also facilitates the process of reading comprehension and helps them retrieve their prior knowledge and background experience easier and faster.

This study investigated the effects of watching text-relevant video segments supported by the Schematic Information-Processing (SIP) model of reading comprehension on reading comprehension of a culturally unfamiliar text with adult speakers of English as a Second Language (ESL). The results of the quantitative analysis, as well as the findings of the qualitative phase, show that the SIP model can be an effective strategy to teach culturally unfamiliar texts in adult English language learning classrooms.

\section{Acknowledgements}

Authors received funding from the Open Access Publishing Fund administered through the University of Arkansas Libraries to cover the Article Processing Charge.

\section{References}

Aferbach, P., Pearson, P. D., \& Paris, P. (2017). Skills and strategies: Their differences, their relationships, and why they matter. In K. Mokhtari (Ed.), Improving reading comprehension through metacognitive reading strategies instruction (pp. 33-50). Lanham, MD: Rowman and Littlefeld.

Akbulut, Y. (2007). Effects of multimedia annotations on incidental vocabulary learning and reading comprehension of advanced learners of English as a foreign language. Instructional Science, 35(6), 499-517. https://doi.org/10.1007/s11251-007-9016-7

Anderson, N. J. (1999). Exploring second language reading: Issues and strategies. Boston, MA: Heinle \& Heinle.

Arthur, P. (1999). Why use video? A teacher's perspective. VSELT, 2(4), 4-16.

Atkinson, R. C., \& Shiffrin, R. M. (1971). The control of short-term memory. Scientific American, 225(2), 82-90. https://doi.org/10.1038/scientificamerican0871-82

August, D., \& Shanahan, T. (2006). Developing literacy in second-language learners: Report of the national literacy panel on language minority children and youth. Mahwah, NJ: Lawrence Erlbaum Associates.

Bohn-Gettler, C. M. (2019). Getting a grip: The PET framework for studying how reader emotions influence comprehension. Discourse Processes, 56(5-6), 386-401. https://doi.org/10.1080/0163853X.2019.1611174

Braun, V., \& Clarke, V. (2006). Using thematic analysis in psychology. Qualitative Research in Psychology, 3(2), 77-101. https://doi.org/10.1191/1478088706qp063oa

Brevik, L. M. (2015). How teachers teach and readers read. Developing reading comprehension in English in Norwegian upper secondary school (Unpublished doctoral dissertation). Oslo, Norway: University of Oslo.

Brevik, L. M. (2019b). Explicit reading strategy instruction or daily use of strategies? Studying the teaching of reading comprehension through naturalistic classroom observation in English L2. Reading and Writing, 32(9), 2281-2310. https://doi.org/10.1007/s11145-019-09951-w

Brown, R. (2017). Comprehension strategies instruction for learners of English: Where we have been, where we are now, where we still might go. In S. E. Israeli (Ed.), Handbook of research on reading comprehension (pp. 543-567). New York, NY: The Guilford Press. 
Canning-Wilson, C. (2000). Practical aspects of using video in the foreign language classroom. The Internet TESL Journal, 4(11).

Carrell, P. L., \& Eisterhold, J. C. (1983). Schema theory and ESL reading pedagogy. TESOL Quarterly, 17(4), 553-573. https://doi.org/10.2307/3586613

Caspi, A., Gorsky, P., \& Privman, M. (2005). Viewing comprehension: students' learning preferences and strategies when studying from video. Instructional Science, 33(1), 31-47. https://doi.org/10.1007/s11251-004-2576-x

Clark, J. M., \& Paivio, A. (1991). Dual coding theory and education. Educational Psychology Review, 3(3), 149-210. https://doi.org/10.1007/BF01320076

Creswell, J. W. (2013). Qualitative inquiry and research design: Choosing among five approaches (3rd ed.). Los Angeles, CA: SAGE Publications.

Cruse, E. (2007). Using educational video in the classroom: Theory, research and practice. Library Video Company.

Droop, M., \& Verhoeven, L. T. (1998). Background knowledge, linguistic complexity, and second-language reading comprehension. Journal of Literacy Research, 30(2), 253-271. https://doi.org/10.1080/10862969809547998

Field, A., Miles, J., \& Field, Z. (2012). Discovering statistics using R. London (UK): Sage Publications.

Fountas, I., \& Pinnell, G. S. (2001). Guiding readers and writers: Teaching reading comprehension, genre, and content literacy. Portsmouth, NH: Heinemann.

Grabe, W., \& Stoller, F., L. (2002). Teaching and researching reading. Harlow, UK: Pearson Education.

Hemei, J. (1997). Teaching with video in an English class. Journal of English Teaching Forum, 35(2), 45-47.

Hollenbeck, A. (2011). Instructional makeover: Supporting the reading comprehension of students with learning disabilities in a discussion-based format. Intervention in School and Clinic, 46(4), 211-220. https://doi.org/10.1177/1053451210389035

Hovland, C. I., Lumsdaine, A. A., \& Sheffield, F. D. (1949). Experiments on mass communication. Princeton University Press: Princeton, NJ. https://doi.org/10.1037/14519-000

Hwang, H., \& Duke, N. K. (2020). Content counts and motivation matters: Reading comprehension in third-grade students who are English learners. AERA Open, 6(1), 1-17. https://doi.org/10.1177/2332858419899075

Karami, A. (2019). Implementing audio-visual materials (videos), as an incidental vocabulary learning strategy, in second/foreign language learners' vocabulary development: A current review of the most recent research. i-manager's Journal on English Language Teaching, 9(2), 60-70. https://doi.org/10.26634/jelt.9.2.15519

Karami, A. (2021). The Schematic Information-Processing (SIP) model of reading comprehension: Theoretical support for the utilization of text-relevant video segments to teach culturally unfamiliar texts in second/foreign language classrooms. Cogent Education, 8(1), 1-25. https://doi.org/10.1080/2331186X.2021.1891613

Karami, A., Bowles, F. A., \& Liggett, C. A. (2021). Text-related video segments and reading comprehension: A brief review of research within the last 20 years. i-manager's Journal on English Language Teaching, 11(1), 40-52. https://doi.org/10.26634/jelt.11.1.17393

Kelley, M. J., \& Clausen-Grace, N. (2007). Comprehension shouldn't be silent: From strategy instruction to student independence. Newark, DE: International Reading Association.

Kintsch, W. (1988). The role of knowledge in discourse comprehension: A construction-integration model. Psychological Review, 95(2), 163-182. https://doi.org/10.1037/0033-295X.95.2.163

Kintsch, W. (1998). Comprehension: A paradigm for cognition. Cambridge University Press.

Kintsch, W., \& van Dijk, T. A. (1978). Toward a model of text comprehension and production. Psychological Review, 85(5), 363-394. https://doi.org/10.1037/0033-295X.85.5.363

Lin, L. F. (2016). The impact of video-based materials on Chinese-speaking learners' English text comprehension. English Language Teaching, 9(10), 1-13. https://doi.org/10.5539/elt.v9n10p1

Ljubojevic, M., Vaskovic, V., Stankovic, S., \& Vaskovic, J. (2014). Using supplementary video in multimedia instruction as a teaching tool to increase efficiency of learning and quality of experience. The International 
Review of Research in Open and Distance Learning, 15(3), 275-291. https://doi.org/10.19173/irrodl.v15i3.1825

Mayer, R. E. (1997). Multimedia learning: Are we asking the right questions? Educational Psychologist, 32(1), 1-19. https://doi.org/10.1207/s15326985ep3201_1

Moreno, R., \& Mayer, R. E. (1999). Cognitive principles of multimedia learning: The role of modality and contiguity. Journal of Educational Psychology, 91(2), 358-368. https://doi.org/10.1037/0022-0663.91.2.358

Nation, K. (2019). Children's reading difficulties, language, and reflections on the simple view of reading. Australian Journal of Learning Difficulties, 24(1), 47-73. https://doi.org/10.1080/19404158.2019.1609272

Osorio, G. (2011). A brief review of American football rules and statistical variables. Sportscience, 15, $25-29$.

Sabatin, I. M. (2013). The effect of cultural background knowledge on learning English language. International Journal of Science Culture and Sport, 1(4), 22-32. https://doi.org/10.14486/IJSCS39

Saldaña, J. (2009). The coding manual for qualitative researchers. Los Angeles, CA: Sage Publications.

Samson, J. F., \& Lesaux, N. (2015). Disadvantaged language minority students and their teachers: A national picture. Teachers College Record, 117(2), 1-26.

Schmider, E., Ziegler, M., Danay, E., Beyer, L., \& Bühner, M. (2010). Is it really robust? Reinvestigating the robustness of ANOVA against violations of the normal distribution assumption. Methodology: European Journal of Research Methods for the Behavioral and Social Sciences, 6(4), 147-151. https://doi.org/10.1027/1614-2241/a000016

Smith, R., Snow, P., Serry, T., \& Hammond, L. (2021). The role of background knowledge in reading comprehension: A critical review. Reading Psychology, 42(3), 214-240.

Snow, C. (2002). Reading for understanding: Toward an R\&D program in reading comprehension. Santa Monica, CA: Rand Corporation.

Spencer, M., \& Wagner, R. K. (2018). The comprehension problems of children with poor reading comprehension despite adequate decoding: A meta-analysis. Review of Educational Research, 88(3), 366-400. https://doi.org/10.3102/0034654317749187

Uttley, J. (2019). Power analysis, sample size, and assessment of statistical assumption improving the evidential value of lighting research. LEUKOS, 15(2-3), 143-162. https://doi.org/10.1080/15502724.2018.1533851

Webb, S., \& Rodgers, M. P. H. (2009a). Vocabulary demands of television programs. Language Learning, 59(2), 335-366. https://doi.org/10.1111/j.1467-9922.2009.00509.x

Wijekumar, K., Meyer, B. J. F., Lei, P., Hernandez, A. C., \& August, D. L. (2018). Improving content area reading comprehension of Spanish speaking English learners in Grades 4 and 5 using web-based text structure instruction. Reading and Writing, 31(9), 1969-1996. https://doi.org/10.1007/s11145-017-9802-9

Wisdom, J., \& Creswell, J. W. (2013). Mixed methods: Integrating quantitative and qualitative data collection and analysis while studying patient-centered medical home models (AHRQ Publication No. 13-0028-EF). Rockville, MD: Agency for Healthcare Research and Quality.

Woolley, G. (2011). Reading comprehension: Assisting children with learning difficulties. London: Springer. https://doi.org/10.1007/978-94-007-1174-7

Wright, A. (1976). Visual materials for the language teacher. Essex, Longman Wilson.

\section{Copyrights}

Copyright for this article is retained by the author(s), with first publication rights granted to the journal.

This is an open-access article distributed under the terms and conditions of the Creative Commons Attribution license (http://creativecommons.org/licenses/by/4.0/). 